\title{
Determinants of Wood Prices: Analysis of Wood Retailers in Kumasi
}

\author{
Collins Kankam-Kwarteng1* , Jacob Donkor², Stephen Acheampong2 \\ ${ }^{1}$ Department of Marketing, Kumasi Polytechnic, Kumasi, Ghana \\ ${ }^{2}$ Ghana Baptist University College, Kumasi, Ghana \\ Email: ${ }^{*}$ colkann@gmail.com
}

Received 11 November 2015; accepted 8 January 2016; published 11 January 2016

Copyright (C) 2016 by authors and Scientific Research Publishing Inc.

This work is licensed under the Creative Commons Attribution International License (CC BY). http://creativecommons.org/licenses/by/4.0/

(c) (i) Open Access

\section{Abstract}

This paper investigates the determinants of wood pricing in Ghana. The purpose of this study is to assess the factors that influence the prices of wood product at the various wood markets and retailers in Kumasi which have large variety of wood and different categories of retailers in the industry. The study employs a survey design where respondents are conveniently selected. A semistructured questionnaire was designed to gather data from the respondents. STATA version 12.0 software and several sets of statistical analyses such as frequency tables, percentages, and mean point values were performed. Linear regression was employed to estimate the determinants of wood product prices in the wood markets and retail outlets in Kumasi metropolis. The findings of this study suggest that, most of the price determining factors have a positive relationship with the price of wood sold whilst others such as quantity of wood sold and low quality wood products have a negative relationship with the price of wood product sold. Based on the findings of the study, the researchers recommend to future researchers to concentrate further studies on how government policies affect wood prices and also types of wood and their influences on prices.

\section{Keywords}

Determinants, Wood, Prices

\section{Introduction}

The importance of capable pricing practice cannot be underrated. The difficulty in pricing in the wood industry can also not be underestimated. The nature of demand, competitiveness, cost, company objective and marketing conditions are the factors that need critical analysis in the Ghanaian wood industry. Such variables may have

"Corresponding author.

How to cite this paper: Kankam-Kwarteng, C., Donkor, J. and Acheampong, S. (2016) Determinants of Wood Prices: Analysis of Wood Retailers in Kumasi. Open Journal of Business and Management, 4, 36-44. 
enormous implication for an industry that faces regulation and pricing difficulties. According to [1] when companies fail to appreciate the implications of their pricing decisions, this often leads to missed opportunities and eventually lower profits. [1] explains that price setting is a multidimensional process which has effects on: customer retention, market share, margin levels, and domestic and international sales. [2] believes that smarter pricing has greater impact on market success than any other element.

Prices of wood products like many other goods can generally be assumed to be determined by demand and supply, where prices adjust to bring demand and supply into balance [3]. Movements in wood product prices have both a long-term and a short-term element. The long-term path is related to long-term trends in demand and supply. In the shorter term, price movements can result from temporary shocks to supply and/or demand conditions. The academic solution to the many pricing variables noticed in the wood market has necessitated this research. For the Ghanaian market, price is influenced by demand and supply conditions on domestic and international markets. For example, downward pressure on prices has, in recent years, been associated with over capacity and over supply of round wood, and some commodity wood products, on a global basis [4]. The study is to identify the critical factors that influence the pricing of wood products in Ghana looking at the situation of wood market and retail outlets in the Kumasi Metropolis.

\section{Literature Review}

\subsection{Concept of Pricing as a Marketing Tool}

Pricing decision is a crucial decision every organization has to make, because this will eventually affect their corporate objectives, either directly or indirectly [5]. For every business entity, irrespective of their line of business and objective, cost minimization and profit maximization is a general factor to be considered and for non-profit making organizations, there will always be the need to reduce cost at all means and to maximize output. A business whether small or big, simple or complex, private or public, is created to provide competitive prices [6]. According to [7], setting the price for an organization's product or service is one of the most crucial decisions a manager faces, and one of the most difficult, due to the number of factors that must be considered. Some of the factors that influence pricing decision are demand, competitors, cost, political, environmental, legal and image-related issues. [8] buttress this point by stating that managers are frequently faced with decisions on pricing and profitability of their products. To understand the wide concept of pricing and it is most relevant elements, a literature review of the pricing elements is needed. The current literature of pricing is full of different viewpoints and theories which are discussed from different angles, this makes it difficult to find widely recognized and agreed elements for the pricing. The problematic part of summarizing the literature is that different authors use different concepts and definitions from the same matters. Hence some generalizations are made which makes it possible that the precise terms used by different author(s) for the different elements are not presented.

\subsection{Pricing Strategy}

Pricing strategy is the reasoned choice from a set of alternative prices (or price schedules) that aim at profit maximization within a planning period in response to a given scenario [9]. [10] described pricing strategy as the interdisciplinary bridge through all business functions: The final determination of value is in the mind of the buyer, while good pricing aims at enhancing the worth of the product so that the value is increased regardless of the price. Understanding of the value of the product to the business of the buyer is necessary while the current competitive situation and expectation of future competitor behavior has to be taken into account.

The pricing strategy is one of the elements widely occurring in the context of pricing by many authors [11]-[13]. However there is no clear definition which is regarded to be a part of pricing strategy or what matters the pricing strategy should include. Also there is a lack of literature made from the wood products pricing point of view. [11] suggest a comprehensive model from the pricing strategy.

In the pricing strategy [11] suggest that there are five main segments which need consideration: Firm, Environment, Distribution Channels, Competition, and Customers. One of the segments is the Firm which contains: corporate objectives, costs, and marketing programs and product assortment. In this segment the authors suggest, that the cost should be evaluated widely in such a way, that it would include costs such as the product production costs and also the marketing costs such as market penetration costs in different areas. The marketing pro- 
gram includes taking into consideration the marketing unit targets about how the products are positioned in the markets. For example are the products unique or standard ones. In the product assortment the products price relationship to other products prices from the same product line are considered.

The second element is the Environment which according to the authors should have an effect on pricing strategy. There can be government regulations such as price control, duty requirements, import taxes or quotes which can have an influence in the pricing possibilities. If the country has hyperinflation and there are price increase limitations, the company should ask for higher possible price from new products. There is also a possibility of currency risks where firms need to analyze the stability of the currency and decide if it is important to revise prices continually or seldom. Also the relative growth or descent of different economies can have an effect on pricing decisions [11].

The third element in pricing strategy consideration is Distribution Channels. One reason for the distribution channel consideration is the distribution costs which can have a noteworthy influence on the offerings eventual price. The gray market re-export risk can also have an effect on pricing. This appears when there are price differences in different areas which enable the possibility for a distributor to overbuy and sell the surplus in different areas profitably [11]. The wood market in Ghana has wide range of distribution network. Retailers in the industry receive supplies from many sources which may influence the pricing structure of the wood products.

The Competitors are a fourth element which is one critical viewpoint to be taken into consideration when exploiting the pricing strategy. In a highly competitive market such as the wood market in Ghana, competition based pricing cannot be underestimated. One essential matter is to compare the companies' offerings benefits and deficiencies closely between competitors. This is not always possible if the bidding is done rarely, which makes it difficult to sustain consciousness about competitors pricing. The second question related to the costs of competitors. This, as well as pricing can be as well as the pricing to prove to be a difficult task [11].

The fifth element in the pricing is the Customer. In this segment the marketing unit should create understanding on how the customers are practicing their business. This is used when the price is constructed with the true value drivers which the customer is valuing to determine the true value-in-use prices. The determination of the value-drivers is not always just the customer's perception from the product but also from the manufacturer itself. Other side of the customer's consideration is the paying ability. If the customer does not have the amount of funds needed to acquire the products or services, alternative payment methods could be used such as: countertrades, or long-term payment programs [11].

A slightly older framework created by [13] is mainly supporting the early presented frameworks point of view and adds also more elements in the pricing strategy consideration. In the authors framework the pricing strategy is di-vided into: Firm-level factors, Product-specific factors, Market-specific factors, and Environmental factors. From the Firm-level factors the authors suggests that consideration in wide area of different cost is needed such as: product development costs, but also there is consideration needed in the experience-curve effects and scaleof-economies which can have an effect on costs. The authors have also wide perspective from the product as a part of the pricing strategy where the authors have suggested that factors such as: product-life-cycle stage and substitutes' evaluation. The authors also include services and deliveries in the product-specific factors. In the Market-specific factors the authors are supporting the earlier presented model where the customer's ability buy, government regulations and distribution channels choice and barriers to trade are considered. In addition the authors also add the consideration of product adoption costs from different markets. In the Environmental factors the authors have included competitor's goals and their possible price signaling.

Pricing strategy is a sophisticated and well-thought-out pricing structure that can help to prevent the product from being commoditized [14]. They argued that, a company's pricing strategy should always be comprehensive; by analyzing the pricing environment in which the company is operating; determining how much pricing discretion the company has, and determining the value the product or service has for customers.

As a conclusion by linking the different pricing strategy point of views presented earlier, the pricing strategy is a widely general area which contains many factors to consider. The factors include matters such as: the market environment which can contain political factors and competition, the firm with its products is needed to compare with to its competitors; also the distribution channel can also be important matter to consider. From the literature covering the area of pricing strategies, there is a lack of literature covering the area of pricing strategies in the context of service pricing. This may be due to generalizability of the two strategic pricing frameworks, where the outlining of products is not considered to be relevant. The application of any of the pricing strategies in the wood products industry in Ghana can add to the continuous development of the pricing literature. 


\subsection{Pricing Objectives}

The subjects of pricing objectives and policies are widely used in the pricing literature to form the guidelines for the pricing. These two matters are taken into consideration by many authors who have made their own pricing models [11] [15]-[17] for this reason it is rational to study these two matters' meanings and usage in pricing.

Because in the literature pricing objectives and pricing methods are strongly related to each-other a clarification of pricing objectives is in order. [18] has defined the pricing objectives as: "they provide direction for action". [19] says from pricing objectives: "To have them is to know what is expected and how the efficiency of the operations is to be measured". The importance of pricing objectives is also presented in the literature. [20] has suggested for pricing objectives that: "they should be the starting point of every pricing effort." [21] also agree with the idea that the first task in pricing is to clarify the objectives. The previously mentioned authors also add that it is not wise to give objectives which can be in conflict for example targeting to achieve maximum profit and maximum market share at the same time, which is not always possible. In sum the literature is generally supporting the statement that the pricing objectives should be clear before the pricing is initiated.

In the literature there is a wide area of different views how on the pricing objectives are set. Normally the pricing objectives can have some specific goals which can be related to: sales profits, return on investment, sales revenues, market size objectives, channel relationship, or product line consideration [17] [21] [22].

[23] have presented that the pricing objectives' eventual outcome is maximum attainable profits which however can be difficult to operationalize. For this reason the pricing objectives used should be intermediaries which would lead to maxi-mum profit levels. The used intermediate objectives should be also established from several different classes such as: profit, consumer satisfaction, competitive vulnerability, strategic consistency, and simplicity of the pricing rules. This gives better tools to operationalize the objectives for pricing [23]. It is also important to recognize that although in the literature the profit orientated objectives are widely understood to be the general goal in pricing [11] argues that some companies do not have the possibility to target objectives such as maximizing the sales profits but only to survive in an industry with a very strong competition and overcapacity.

Pricing objectives can be divided into six different categories relating to their content. These categories are: quantitative objectives qualitative objectives, objectives with maximum level of attainment, objectives with satisfactory, level of attainment, short-term objectives and long-term objectives [20]. In the authors model both qualitative and quantitative pricing objectives can be used. Quantitative objectives can be measured easily and can be related to: profits, sales, market shares and costs coverage. Qualitative objectives can be related to relationship: with customers, competitors, distributors, the long-term survival of the firm, or achievement of social goals. The desired level of attainment can be divided mainly in two categories: those which need maximum results and those where satisfactory results are accepted. The time horizon of the pricing objectives can be divided to long- and short-term ones. The short-term objectives strive to fulfill specific goals for a short term i.e. six months' time period. The long-term objectives can be achieved after a longer time-period [20]. The objectives classification presented above is one way to identify and categorize the pricing objectives to six different categories. However, many authors are suggesting that because of the complexity of pricing decisions, there is a need to use more than one pricing objective at a time [18] [20].

\section{Research Instrumentation}

\subsection{Research Design}

The study adopted case study design since it is useful in investigating a contemporary phenomenon [24], and the contemporary phenomenon under investigation in this study is 'an assessment of factors that influence the pricing of wood products. Moreover the case study design offers an opportunity to gather data from various sources [25], and this would make the study more reliable. To satisfy the principles of multi data sources, the study selected retail outlets of wood products that are scattered in the Kumasi metropolis.

\subsection{Sampling Issues for the Study}

The researchers assessed the factors that influence the pricing of wood products in the wood markets and outlets across the city. The targeted population for the study consisted of retailers and suppliers of wood products in the Kumasi metropolis.

The primary data for the study was generated by means of a well-structured questionnaire instrument. The 
first section of the questionnaire was based on the personal data of the responses while the second section of the questions sought to relate to the subject matter on the basis of the research questions. The questions in the questionnaire were focused on the relationship between factors in the wood product markets and their influence on pricing variables in the wood product market. The questionnaire was carefully administered and a total of hundred and twenty three (123) respondents were selected for the purpose of this study.

Simple random technique was adopted for this study to ensure that each member in the population will have equal chance of being selected. The sampling was done randomly such that the respondents represented the entire players in the value chain process of the wood product market. This could to some extent give a basis for generalization. The survey was carried at the various wood retail outlets in the Kumasi metropolis.

\subsection{Data Analysis Technique}

Completed questionnaire from the field was edited and coded appropriately to make meaning out of them. Data cleaning was performed to correct errors, check for non-responses and accuracy and remove outliers. Coding was done to facilitate a comprehensive analysis of the data. To arrive at the intended analysis, the responses were keyed into STATA version 12.0 software and several sets of statistical analyses such as percentages, and mean point values were performed. Linear regression was employed to estimate the determinants of wood product prices in the wood markets and retail outlets in Kumasi.

\section{Empirical Results and Discussion of Findings}

\subsection{Analysis of Demographic Characteristics of Respondents}

With respect to socio-demographic characteristics, key information that the study intended including were age, gender, level of education etc. Findings obtained from this analysis are shown in the Table 1 below.

Table 1 shows the results on the socioeconomic characteristics of the respondents used for the study. The results revealed that most of the respondents (32.52\%) are within the ages of 30 - 39 years; $30.89 \%$ of the respondents are in the ages of $40-49$ years whilst $30.08 \%$ of the respondents are in the ages of $20-29$ years and $6.5 \%$ of the respondents are within the ages of 50 years and above. Considering the gender distribution of the respondents, it was observed that majority (60.98\%) of the sampled respondents are males whilst the least (39.02\%) of the respondents are females. This means that the point of generalizations of this study reflects more on the views

Table 1. Percentage distribution of descriptive statistics.

\begin{tabular}{ccc}
\hline Variable & Frequency (N) & Percentage (\%) \\
\hline Age & 37 & 30.08 \\
$20-29$ & 40 & 32.52 \\
$30-39$ & 38 & 30.89 \\
$40-49$ & 8 & 6.50 \\
$\geq 50$ years & & 60.98 \\
Gender & 75 & 39.02 \\
Male & 48 & 12.20 \\
Female & & 16.26 \\
Education & 15 & 45.53 \\
Tertiary & 20 & 16.26 \\
Secondary education & 56 & 9.76 \\
Technical/Vocational & 20 & \\
MSLC/JHS & 12 & \\
No formal Education & & \\
\hline
\end{tabular}

Source: Author's computation, 2015. 
of male wood retailers than their female counterpart in the industry. With regards to the educational qualification of the respondents, the study revealed that majority (45.53\%) of the respondents have attained Secondary Education; 20 (16.26\%) of the respondents have attained Technical/Vocational education whilst another 20 (16.26\%) were within the category of MLCE/JHS qualification, 15 (12.20\%) attained a tertiary qualification and 12 (9.76\%) of the respondents have no formal education. In the wood industry it is to be expected that majority have formal education, even though it is within the bracket of MSLC and secondary and technical education. The educational background provides the study with the extent to which respondents appreciate their pricing practices and their implication on the wood industry.

\subsection{Summary Statistics}

The study sought to find the summary statistics of the variables used in the price determinants model. The findings of this analysis are shown in the Table 2 below.

Table 2 shows the results of the summary statistics obtained for the variables used in the model. The results indicate that the mean quantity of wood sold per month by the wood dealers in the study area is 1613.9 pieces and this lies within the ranges of 150 and 2579 pieces respectively. Considering the transportation cost, it was found that the mean transportation cost incurred by the wood dealers is GH\$1500.1 lying within the price ranges of GH\$269 and GH\$3919 respectively. The study also revealed that the mean carriage cost per month was GH\$157.3 and this again lies within the ranges of GH\$101 and GH\$905 respectively. With regards to seasoning cost, it was observed that the mean seasoning cost per month incurred by the wood dealers was GH\$2100 and this lies within the range of GH\$2791 and GH\$5000 respectively. Lastly, it was observed that the mean price per piece of wood was GH\$45.3 and this was found to lie within the price range of GH\$33.5 and GH\$90.1 respectively.

\subsection{Determining Factors of Wood Prices}

After the researchers had determined the knowledge base of respondents on wood prices and wood price determining factors, the researchers further went on to determine the correlation between wood price determining factors (independent variable) and prices of wood (dependent variable) of the wood dealers and retailers in Kumasi by the use of Pearson rank correlation coefficient (Table 3).

The Pearson rank correlation was calculated for each price determining factor in the wood product industry. The results in table 4.3 show that the correlation between quantity of wood sold per month by the wood dealers and the prices of wood is -0.962 and highly significant at $1 \%(0.01)$ level of testing. This implies that there is a negative significant relationship between the quantity of wood sold per month and the price of wood. Thus it can be concluded that as the prices of wood increase, the quantity of wood sold decreases since consumers of these wood product tend to reduce the quantity of wood they buy as a result of higher prices. Again, it was also observed that the correlation for transportation cost is 0.756 and highly significant at $1 \%$ level of testing implying that there is a strong positive correlation between the cost of transporting wood to sales point and the prices at which the dealers sell the wood. Thus, it can be concluded that as the cost of transporting the wood increases, the prices of wood product increase since the wood dealers tend to pass on the extra cost of transportation to the consumers (buyers) of the wood product. Considering carriage cost, a correlation coefficient of 0.791 was obtained between carriage cost and the price of wood product and this is highly significant at $1 \%$ level of testing. This implies that there is a strong correlation between carriage cost and the price of wood sold. Hence, like in

Table 2. Summary statistics of the variables used in the model.

\begin{tabular}{|c|c|c|c|c|}
\hline Variable & Unit & Mean & Min & $\operatorname{Max}$ \\
\hline Quantity & Pieces/Month & 1613.9 & 150 & 2579 \\
\hline Transportation & $\mathrm{GH} \overleftarrow{4}$ & 1500.1 & 269 & 3919 \\
\hline Carriage cost & $\mathrm{GH}$ & 157.3 & 101 & 905 \\
\hline Seasoning cost & $\mathrm{GH}$ & 2100 & 2791 & 5000 \\
\hline Price & $\mathrm{GHC}$ & 45.3 & 33.5 & 90.1 \\
\hline
\end{tabular}

Source: Author's computation, 2015. 
Table 3. Correlation matrix for price and the determinant factors.

\begin{tabular}{cccccc}
\hline Variable & Price & Qty. & TC & CC & SC \\
\hline Price & 1 & $-0.962^{* * *}$ & $0.756^{* * *}$ & $0.791^{* * *}$ & $0.818^{* * *}$ \\
Qty. & 1 & $0.690^{* * *}$ & 0.299 & 0.216 & \\
TC & 1 & $0.813^{* * *}$ & $0.742^{* * *}$ & & \\
CC & 1 & $0.801^{* * *}$ & & & \\
SC & 1 & & & & \\
\hline
\end{tabular}

Source: Author's computation, $2015\left({ }^{* * *}\right.$ indicates correlation is significant at the $1 \%$ level). Note: Qty. = Quantity Sold per month; TC = Transportation Cost; $\mathrm{CC}=$ Carriage Cost and SC $=$ Seasoning Cost.

the case of transportation cost, it can be inferred that as the cost of carriage increases, the price of wood sold also increases because the wood dealers tend to pass on the extra cost of carriage to the final consumers (buyers) of the wood. Lastly the study revealed that the correlation between seasoning cost and the price of wood sold was 0.818 and this is highly significant at $1 \%$. This also implies that there is a strong positive correlation between seasoning cost and the price of wood sold.

\subsection{Ordinary Least Square Analysis}

In assessing the effect of price determining factors and the price of wood sold by the dealers, an Ordinary Least Square (OLS) regression model was adopted for the analysis. The results of the OLS are shown in Table 4.

The results in Table 4 shows the findings of the effect of the factors that influence wood prices on the prices of wood sold by the dealers at the wood markets and retailers in Kumasi. The results indicates that all the primary factors that influence wood prices are positively related to the price of wood sold at the wood village except the quantity of wood sold per month and are all significant at $1 \%$ and $10 \%$ level of testing respectively. This implies that an effective management of these primary price determining factors by the dealers will have a positive significant impact on the sales revenue generated by the wood dealers in the village. The negative coefficient of the quantity of wood sold by the dealers confirms the basic demand theory (price and quantity negativity relationship) and it implies that an increase in the prices of wood sold will cause a relative decrease in the quantity of wood sold since consumers tend to reduce the quantity of wood they purchase as a result of the increase in prices.

\subsection{The High Quality Type}

The results in Table 4 also shows the findings of the effect of quality of wood sold on the prices of wood sold at the wood village. The results indicates that all high quality type of wood are positively related to the prices of the wood sold at the wood village and are all significant at $1 \%$ and $5 \%$ level of testing respectively. This implies that there is a positive relationship between the high quality standard of the wood sold and the corresponding prices. This further indicates that as the dealers put more and more quality wood product onto the market, the price of wood products increases since the high quality product tend to be highly priced relative to the low quality wood products.

\subsection{The Low Quality Wood Type}

The results in Table 4 finally show the findings of the effect of low quality wood product on the wood market. The results indicates that all the low quality wood products are negatively related to the prices of wood sold on the market and are all significant at 1\%, 5\% and 10\% level of testing respectively. This implies that as more low quality wood products are put on the market, the prices of wood commodity sold declines since the wood market tends to be dominated by low quality product. From the analysis, the coefficient of determination (R-squared) was estimated to be 0.9369 and was highly significant at $1 \%$ level of testing. This implies that $93.69 \%$ of the variations in the prices of wood sold is explained by the wood determining factors captured in the model whilst the remaining $6.31 \%$ is explained by factors beyond the control of the wood dealers such as inflation, natural 
Table 4. Ordinary least square analysis on the factors that influence the price of wood.

\begin{tabular}{|c|c|c|c|c|}
\hline Variables & Coef. & Std. Error & t-Value & P-Value \\
\hline \multicolumn{5}{|l|}{ Primary Factors } \\
\hline Qty. & $-0.4483^{* * *}$ & 0.1326 & -3.38 & 0.004 \\
\hline Transportation & $0.6899^{* * * *}$ & 0.1310 & 5.27 & 0.000 \\
\hline Carriage Cost & $0.2932^{* * *}$ & 0.1221 & 2.40 & 0.009 \\
\hline Seasonal Cost & $0.1017^{*}$ & 0.0576 & 1.77 & 0.096 \\
\hline \multicolumn{5}{|l|}{ High Quality Type } \\
\hline Odum & $0.8550^{* * *}$ & 0.0996 & 8.59 & 0.000 \\
\hline Dahoma & $0.4891^{* * *}$ & 0.1187 & 4.12 & 0.000 \\
\hline Mahogany & $0.2191^{* *}$ & 0.1076 & 2.04 & 0.042 \\
\hline Mansonia & $0.1964^{* * * *}$ & 0.0503 & 3.91 & 0.000 \\
\hline Wawa & $0.1953^{* * *}$ & 0.0217 & 9.02 & 0.000 \\
\hline \multicolumn{5}{|l|}{ Low Quality Type } \\
\hline Otie & $-0.0339^{*}$ & 0.0198 & -1.71 & 0.087 \\
\hline Yaya & $-0.0797^{* * *}$ & 0.0293 & -2.72 & 0.007 \\
\hline Chenchen & $-0.0789^{* *}$ & 0.0305 & -2.59 & 0.010 \\
\hline Waterpou & $-0.1057^{* * *}$ & 0.0252 & -4.19 & 0.000 \\
\hline Cebia & $-0.0403^{*}$ & 0.0222 & -1.81 & 0.070 \\
\hline Constant & 0.9715 & 0.0483 & 20.12 & 0.000 \\
\hline$N$ & 90 & & & \\
\hline F-Statistics & 61.31 & & & \\
\hline$P>F$ & 0.0000 & & & \\
\hline$R$-Squared & 0.9369 & & & \\
\hline Adj. R-Squared & 0.9279 & & & \\
\hline
\end{tabular}

Source: Author's computation $\left({ }^{* * *},{ }^{* *}\right.$ and ${ }^{*}$ indicate significance at $1 \%, 5 \%$ and $10 \%$ respectively).

disaster, seasonal changes etc.

\section{Conclusions}

Research on factors that affect wood pricing and the price of wood products sold has progressively become the yardstick for the development of the local wood industry in the Ghanaian private wood business sector. Employing effective research techniques include the attempts to measure efficient and effective wood pricing practices in Ghanaian Wood industry.

It was realized that the types of wood have greater influence in determining pricing of wood products since they consider some wood to be of good quality than others. Cost of transportation also plays a significant role in the pricing of the wood product. Suppliers and retailer should therefore come together to form association in order to come out with a standardised transportation cost.

\section{Suggestion for Future Studies}

In this study the research sought to investigate factors that influence pricing of wood product in Ghana with specific reference to wood products markets and outlets in Kumasi. The study though has established grounds for understanding pricing practices in the wood industry in Ghana, it also important that future researchers take into consideration government policies on wood and how they affect pricing in the Ghanaian wood market. For the 
purposes of expanding knowledge in the field of wood pricing, future researchers can also revise and study the wood market through comparative analysis of sources of supplier of the wood to the various market.

A future study can also build models on the value of individual brand of the various woods on the market. The current study established that there are many brands of wood on the market. This means that the value frame of specific type of wood can be studied for the purposes of building theories in the wood pricing literature.

\section{References}

[1] Lancioni, R. (2005) Pricing Issues in Industrial Marketing. Industrial Marketing Management, 34, 111-114. http://dx.doi.org/10.1016/j.indmarman.2004.07.009

[2] Cram, T. (2006) The Art of Smarter Pricing. Market Leader, Spring, 55-58.

[3] Araujo, M., Kant, S. and Cauto, L. (2009) Why Brazilian Companies Are Certifying Their Woods? Wood Policy and Economics.

[4] Birikorang, G. (2001) Ghana Wood Industry Study and Log Export Ban Study. Wood Commission, Accra.

[5] Monroe, K.B. (2003) Pricing-Making Profitable Decisions. 3rd Edition, McGraw Hill/Irwin, New York.

[6] Ayozie, D.O. (2008) The Role of Small Scale Industry in National Development in Nigeria. ICAN Students' Journal, 12, 10-17.

[7] Hilton, R.W. (2005) Managerial Accounting: Creating Value in a Dynamic Business Environment. McGraw Hill, New York.

[8] Horngren, C.T., Foster, G. and Datar, S.M. (1996) Cost Accounting: A Managerial Emphasis. Prentice Hall, New Delhi.

[9] Tellis, G.J. (1986) Beyond the Many Faces of Price: An Integration of Pricing Strategies. Journal of Marketing, 50, 146-160. http://dx.doi.org/10.2307/1251292

[10] Engelson, M. (1995) Pricing Strategy: An Interdisciplinary Approach. Joint Management Strategy, USA.

[11] Blythe, J. and Zimmerman, A. (2005) Business to Business Marketing Management: A Global Perspective. Thomson, London, $312 \mathrm{p}$.

[12] Hutt, M. and Speh, T. (2010) Business Marketing Management: B2B. Tenth Edition, Cengage Learning, Canada.

[13] Trepstra, V. and Sarathy, R. (2000) International Marketing. 8th Edition, Dryden Press, Fort Worth, 753 p.

[14] Zhang, J. and Raju, J. (2003) Choosing the Wrong Pricing Strategy Can Be a Costly Mistake. http://knowledge.wharton.upenn.edu/article/choosing-the-wrong-pricing-strategy-can-be-a-costly-mistake/

[15] Kotler, P. and Keller, K.C. (2006) Marketing Management. 12th Edition, Prentice Hall \& Pearson Education, Upper Saddle River, 729 p.

[16] Jobber, D. (2010) Principles and Practice of Marketing. 3rd Edition. McGraw-Hill Education, London, 946 p.

[17] Hutt, M. and Speh, T. (2009) Business Marketing Management. 10th Edition. South-Western, Cengage Learning, Cincinnati, $652 \mathrm{p}$.

[18] Oxenfeldt, A.R. (1983) Pricing Decisions: How They Are Made and How They Are Influenced. Management Review, 23-25.

[19] Tzokas, N., Hart, S., Argouslidis, P. and Saren, M. (2000) Industrial Export Pricing Practices in the UK. Industrial Marketing Management, 29, 191-204. http://dx.doi.org/10.1016/S0019-8501(98)00045-5

[20] Diamantopoulos, A. (1991) Pricing: Theory and Evidence-A Literature Review. In: Baker, M.J., Ed., Perspectives on Marketing Management, Wiley, London, 61-193.

[21] Gabor, A. and Granger, C.W.J. (1973) A Systematic Approach to Effective Pricing. Management Decision, 17, 742760.

[22] McCarthy, E.J. and Perrault, W.D. (2002) Basic Marketing: A Global Managerial Approach. McGraw-Hill, New York, $350 \mathrm{p}$.

[23] Cannon, H.M. and Morgan, F.W. (1990) A Strategic Pricing Framework. Journal of Services Marketing, 4, $19-30$. http://dx.doi.org/10.1108/EUM0000000002508

[24] Frankfort-Nachmias, C. and Nachmias, D. (1996) Research Methods in the Social Sciences. Fifth Edition, Arnold, London.

[25] Yin, R. (2009) Case Study Research: Design and Methods. 6th Edition, Sage Publishing, Beverly Hills. 